Journal of Patient-Centered

\title{
Development and Validation of a Preprocedural Risk Score to Predict Access Site Complications After Peripheral Vascular Interventions Based on the Vascular Quality Initiative Database
}

\author{
Daniel Ortiz \\ Maharaj Singh \\ Arshad Jahangir \\ Suhail Allaqaband \\ Anjan Gupta \\ Tanvir Bajwa \\ Mark W. Mewissen
}

Follow this and additional works at: https://aah.org/jpcrr

Part of the Cardiology Commons, Cardiovascular Diseases Commons, and the Surgical Procedures, Operative Commons

\section{Recommended Citation}

Ortiz D, Singh M, Jahangir A, Allaqaband S, Gupta A, Bajwa T, Mewissen MW. Development and validation of a preprocedural risk score to predict access site complications after peripheral vascular interventions based on the Vascular Quality Initiative database. J Patient Cent Res Rev. 2016;3:20-29. doi: 10.17294/ 2330-0698.1208

Published quarterly by Midwest-based health system Advocate Aurora Health and indexed in PubMed Central, the Journal of Patient-Centered Research and Reviews (JPCRR) is an open access, peer-reviewed medical journal focused on disseminating scholarly works devoted to improving patient-centered care practices, health outcomes, and the patient experience. 


\title{
Development and Validation of a Preprocedural Risk Score to Predict Access Site Complications After Peripheral Vascular Interventions Based on the Vascular Quality Initiative Database
}

\author{
Daniel Ortiz, MD, ${ }^{1}$ Maharaj Singh, $\mathrm{PhD},{ }^{1}$ Arshad Jahangir, $\mathrm{MD},{ }^{2}$ Suhail Allaqaband, MD, ${ }^{1}$ \\ Anjan Gupta, MD, ${ }^{1}$ Tanvir Bajwa, MD, ${ }^{1}$ Mark W. Mewissen, MD $^{3}$ \\ ${ }^{1}$ Aurora Cardiovascular Services, Aurora Sinai/Aurora St. Luke's Medical Centers, University of Wisconsin School of \\ Medicine and Public Health, Milwaukee, WI \\ ${ }^{2}$ Sheikh Khalifa bin Hamad Al Thani Center for Integrative Research on Cardiovascular Aging, Aurora University of \\ Wisconsin Medical Group, Milwaukee, WI \\ ${ }^{3}$ Aurora Health Care Vascular Center, Aurora St. Luke's Medical Center, Milwaukee, WI
}
Purpose Access site complications following peripheral vascular intervention (PVI) are associated with prolonged hospitalization and increased mortality. Prediction of access site complication risk may optimize PVI care; however, there is no tool designed for this. We aimed to create a clinical scoring tool to stratify patients according to their risk of developing access site complications after PVI.

Methods The Society for Vascular Surgery's Vascular Quality Initiative database yielded 27,997 patients who had undergone PVI at 131 North American centers. Clinically and statistically significant preprocedural risk factors associated with in-hospital, post-PVI access site complications were included in a multivariate logistic regression model, with access site complications as the outcome variable. A predictive model was developed with a random sample of 19,683 (70\%) PVI procedures and validated in 8,314 (30\%).

Results Access site complications occurred in 939 (3.4\%) patients. The risk tool predictors are female gender, age $>70$ years, white race, bedridden ambulatory status, insulin-treated diabetes mellitus, prior minor amputation, procedural indication of claudication, and nonfemoral arterial access site (model c-statistic = 0.638). Of these predictors, insulin-treated diabetes mellitus and prior minor amputation were protective of access site complications. The discriminatory power of the risk model was confirmed by the validation dataset $(c$-statistic $=0.6139)$. Higher risk scores correlated with increased frequency of access site complications: $1.9 \%$ for low risk, $3.4 \%$ for moderate risk and $5.1 \%$ for high risk.

Conclusions The proposed clinical risk score based on eight preprocedural characteristics is a tool to stratify patients at risk for post-PVI access site complications. The risk score may assist physicians in identifying patients at risk for access site complications and selection of patients who may benefit from bleeding avoidance strategies. (J Patient-Centered Res Rev. 2016;3:20-29.)

Keywords peripheral vascular intervention; hematoma; pseudoaneurysm; risk score

Puncture site hematomas associated with and without pseudoaneurysm are the most common complication in patients undergoing peripheral vascular intervention (PVI) and result in increased length of hospitalization, discharge to nursing home and rehabilitation, and inhospital and long-term mortality. ${ }^{1-5}$ Many models have

Correspondence: Mark W. Mewissen, MD,

2801 W. Kinnickinnic River Parkway, \#330, Milwaukee, WI,

53215, T: 414-385-2429, F: 414-385-2461,

Email: publishing11@aurora.org been developed to calculate patient risk for bleeding complications after percutaneous coronary intervention (PCI) to assist clinicians in using bleeding avoidance strategies in patients at higher risk. ${ }^{6-11}$ Although patients with coronary disease undergoing PCI have similar comorbidities as patients with PCI undergoing PVI, prior studies have shown that risk factors for PVI access site complications (ASC) differ from those for patients undergoing PCI. ${ }^{12}$ Presently, no preprocedural tool exists to assess patients for risk of post-PVI ASC. Using data from the Society for Vascular Surgery 
Patient Safety Organization's Vascular Quality Initiative (VQI), we identified clinical risk factors for post-PVI ASC and developed and validated a clinical tool to predict patient risk.

\section{METHODS}

\section{Study Population}

This study retrospectively analyzed data for 36,529 PVI procedures performed from August 2007 to January 2014 in 131 American and Canadian centers participating in the VQI. A description of the VQI has been previously published. ${ }^{13}$ Immediate and in-hospital events were collected by personnel or providers involved in each patient's care at each center participating in the VQI, or via retrospective chart review by designated data entry personnel. ASCs were site-determined by examination of the medical record, and validation occurred when fields were filled with data outside preset parameters and by comparison with billing information. De-identified data were analyzed and individual patient consent was not obtained. Aurora Health Care's Institutional Review Board prospectively approved the study.

\section{Definitions}

ASC was defined as the presence of a hematoma at the procedural puncture site associated with or without pseudoaneurysm prior to discharge and classified as requiring no intervention or requiring blood transfusion, thrombin injection or operation. Diabetic patients were analyzed by their treatment regimen: no insulin (i.e. diet and lifestyle modification and oral hypoglycemic medications) or on insulin. Procedural urgency was considered emergent if the patient was treated within hours of presentation, urgent if treatment was expected in the same hospital stay, or elective if it was scheduled on an outpatient basis. Indications consisted of claudication, rest pain, tissue loss or acute ischemia.

\section{Statistical Methods}

All categorical variables were described as frequencies and percentages and compared using chi-square tests. Continuous variables were described as mean, range and standard deviation and were compared using t-test. Only one procedure was randomly included for patients with multiple PVIs, and patients who died or transferred to another hospital were excluded as they represent a censured population (Figure 1). Missing data across all the covariates was $5.6 \%$ overall, and patients with missing data related to age, gender, race, smoking history, body mass index, ambulatory status, diabetes, dialysis dependence, procedural indication and urgency, arterial access site, ASC, prior aneurysm repair, prior amputation or prior PVI were excluded. A random sample comprising $70 \%(n=19,683)$ of patients was used as derivation data to develop the predictive model, and the remaining $30 \%(n=8,314)$ of the study group was used to validate the model.

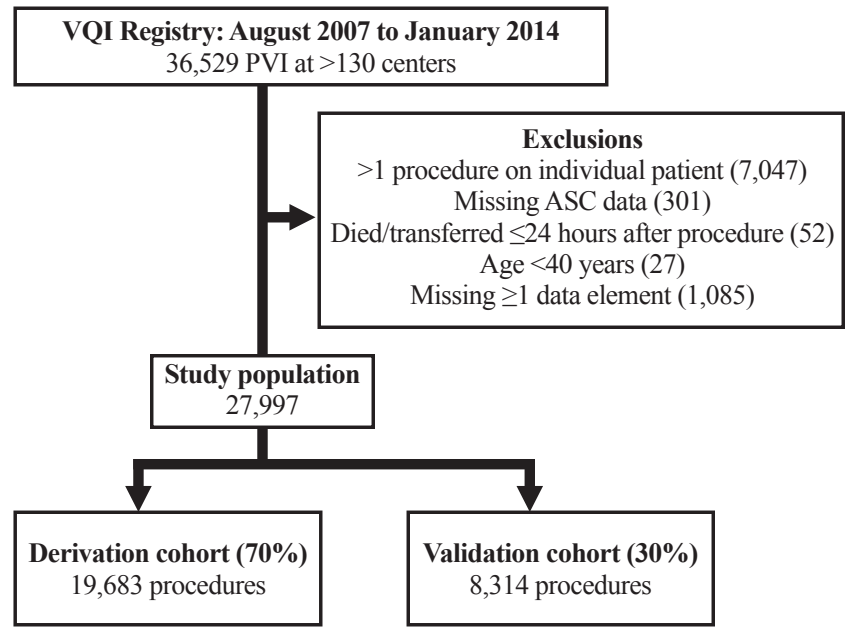

Figure 1. Population flow diagram displaying which patients were included and excluded from the study. ASC, access site complication; PVI, peripheral vascular intervention; VQI, Vascular Quality Initiative.

Based on prior association to ASC and clinical relevance, preprocedural characteristics were selected for initial analysis (Table 1). Continuous variables were plotted against rates for ASC to create dichotomous cut-off points at which relationships became flat or nonlinear. Thirteen characteristics were then entered in the initial multivariate logistic regression model with post-PVI ASC as the binary outcome variable. C-statistics and the Hosmer-Lemeshow test were used to test the goodness-of-fit for the model. Backward selection was then used with a criterion of keeping $\mathrm{P}<0.05$, which resulted in the removal of five variables: body mass index, dialysis dependence, smoking history, prior PVI and prior aneurysm repair. This model was applied to the remaining $30 \%$ of patients, and c-statistics and Brier score were used to validate the model. The ASC risk score was derived from this model by converting $\beta$ coefficients into integers and adding these eight integers for each individual patient to determine their ASC risk. From observation of the ASC risk distribution in the 
derivation cohort $(\mathrm{n}=19,683)$, three risk categories low, medium and high — were subjectively defined.

Given the importance of diabetes in the pathogenesis of PVI and the potential for confounding that treatment of diabetes and its complications may present, it was decided a priori to apply propensity score matching to assess ASC risk compared to nondiabetics. Demographic, clinical and procedural variables were included in a logistic regression model to predict a patient being diabetic

Table 1. Variables considered in modeling process

\begin{tabular}{|c|}
\hline $\begin{array}{l}\text { Demographics } \\
\text { Age (years)* } \\
\text { Gender } \\
\text { Race } \\
\text { Hispanic/Latino ethnicity } \\
\text { Body mass index* }\end{array}$ \\
\hline $\begin{array}{l}\text { Social history } \\
\text { Living status (home or other) } \\
\text { Preoperative ambulatory status } \\
\text { Smoking }\end{array}$ \\
\hline $\begin{array}{l}\text { Home medications } \\
\text { Aspirin } \\
\text { P2Y12 antagonist } \\
\text { Chronic anticoagulant }\end{array}$ \\
\hline $\begin{array}{l}\text { Medical history } \\
\text { Congestive heart failure } \\
\text { Chronic obstructive pulmonary disease } \\
\text { Hypertension } \\
\text { Diabetes } \\
\text { Dialysis } \\
\text { Coronary artery disease } \\
\text { American Society of Anesthesiologists physical status class }\end{array}$ \\
\hline $\begin{array}{l}\text { Laboratory results } \\
\text { Creatinine clearance* (Cockcroft-Gault formula) } \\
\text { Hemoglobin* }\end{array}$ \\
\hline $\begin{array}{l}\text { Surgical/Interventional history } \\
\text { Coronary artery bypass } \\
\text { Percutaneous coronary intervention } \\
\text { Lower extremity bypass } \\
\text { Carotid endarterectomy } \\
\text { Lower extremity aneurism repair } \\
\text { Carotid endarterectomy } \\
\text { Lower extremity aneurism repair } \\
\text { Peripheral vascular intervention } \\
\text { Major lower extremity amputation } \\
\text { Minor lower extremity amputation }\end{array}$ \\
\hline $\begin{array}{l}\text { Periprocedural } \\
\text { Indication } \\
\text { Urgency } \\
\text { Arterial access site (femoral or nonfemoral) }\end{array}$ \\
\hline
\end{tabular}

${ }^{*}$ Analyzed as a continuous and categorical variable. versus nondiabetic conditioned on the covariates found in Table 2. We performed a 1:1 match on the logit of the propensity score to four digits $(0.0001)$ of the probability of being diabetic. Conditional logistic regression was used to produce odds ratios (OR) and 95\% confidence intervals (CI). Using the same method, a separate analysis compared diabetics treated with insulin versus nondiabetics and diabetics not taking insulin.

To study the relationship of antithrombotic agents and closure devices by preprocedural risk, an unmatched subpopulation analysis was achieved by applying

Table 2. Variables matched in the insulin-treated diabetes propensity analysis

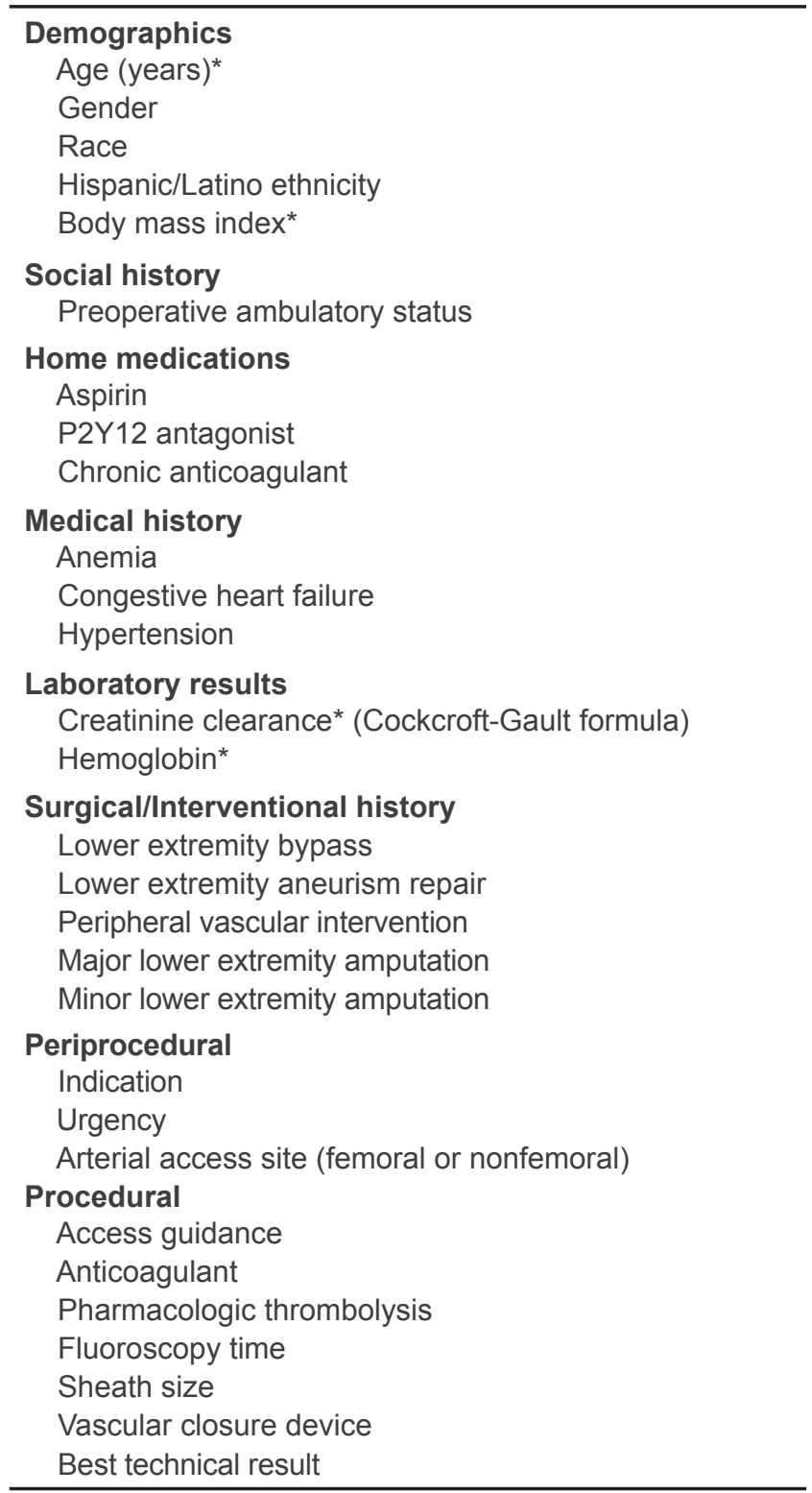

*Analyzed as a continuous and categorical variable. 
Table 3. Patient demographic and clinical characteristics at time of procedure

\begin{tabular}{|c|c|c|c|}
\hline & $\begin{array}{c}\text { Derivation cohort } \\
(n=19,683)\end{array}$ & $\begin{array}{c}\text { Validation cohort } \\
(n=8,314)\end{array}$ & $P$ \\
\hline Mean age \pm SD (range) & $68.13 \pm 11.30(30-89)$ & $67.99 \pm 11.27(30-89)$ & 0.36 \\
\hline$\leq 70$ years & $57.8 \%$ & $57.7 \%$ & 0.90 \\
\hline$>70$ years & $42.2 \%$ & $42.3 \%$ & \\
\hline Gender & & & 0.18 \\
\hline Male & $58.4 \%$ & $59.2 \%$ & \\
\hline Female & $41.7 \%$ & $40.8 \%$ & \\
\hline \multicolumn{4}{|l|}{ Race } \\
\hline Hispanic & $5.7 \%$ & $5.8 \%$ & 0.58 \\
\hline White & $79.2 \%$ & $79.2 \%$ & 0.97 \\
\hline Black & $12.8 \%$ & $12.4 \%$ & 0.31 \\
\hline Other & $2.3 \%$ & $2.6 \%$ & 0.21 \\
\hline \multicolumn{4}{|l|}{ Body mass index } \\
\hline$<18.5$ & $4.1 \%$ & $3.6 \%$ & 0.067 \\
\hline $18.5-24.9$ & $30.2 \%$ & $29.7 \%$ & 0.45 \\
\hline 25-29.9 & $33.9 \%$ & $34.3 \%$ & 0.48 \\
\hline$\geq 30.0$ & $31.9 \%$ & $32.4 \%$ & 0.43 \\
\hline \multicolumn{4}{|l|}{ Smoking status } \\
\hline No smoking & $20.8 \%$ & $20.8 \%$ & 0.97 \\
\hline Prior & $40.7 \%$ & $40.9 \%$ & 0.84 \\
\hline Current & $38.5 \%$ & $38.4 \%$ & 0.86 \\
\hline History of hypertension & $87.1 \%$ & $87.3 \%$ & 0.69 \\
\hline \multicolumn{4}{|l|}{ Diabetes } \\
\hline None & $51.5 \%$ & $51.6 \%$ & 0.874 \\
\hline On oral hypoglycemic & $22.1 \%$ & $22.1 \%$ & 0.912 \\
\hline On insulin & $26.4 \%$ & $26.2 \%$ & 0.776 \\
\hline Chronic obstructive pulmonary disease & $23.3 \%$ & $23.8 \%$ & 0.34 \\
\hline Documented coronary artery disease & $30.1 \%$ & $29.9 \%$ & 0.84 \\
\hline Peritoneal dialysis or hemodialysis & $7.0 \%$ & $6.7 \%$ & 0.44 \\
\hline Symptomatic congestive heart failure & $6.9 \%$ & $6.8 \%$ & 0.79 \\
\hline \multicolumn{4}{|l|}{ Preoperative ambulatory status } \\
\hline Ambulatory & $79.7 \%$ & $80.1 \%$ & 0.41 \\
\hline Ambulatory with assistance & $14.4 \%$ & $13.9 \%$ & 0.31 \\
\hline Wheelchair-bound & $5.2 \%$ & $5.2 \%$ & 0.99 \\
\hline Bedridden & $0.8 \%$ & $0.8 \%$ & 0.78 \\
\hline Prior subinguinal bypass & $16.1 \%$ & $15.1 \%$ & 0.052 \\
\hline Prior peripheral vascular intervention & $29.5 \%$ & $29.5 \%$ & 0.96 \\
\hline Prior minor lower extremity amputation & $7.7 \%$ & $6.9 \%$ & 0.018 \\
\hline Prior major lower extremity amputation & $4.3 \%$ & $4.3 \%$ & 0.96 \\
\hline Prior $\mathrm{PCl}$ & $22.3 \%$ & $21.7 \%$ & 0.39 \\
\hline Prior coronary artery bypass graft & $21.6 \%$ & $21.2 \%$ & 0.52 \\
\hline \multicolumn{4}{|l|}{ Preoperative medications } \\
\hline Aspirin & $72.7 \%$ & $72.3 \%$ & 0.40 \\
\hline P2Y12 antagonists & $32.5 \%$ & $32.9 \%$ & 0.57 \\
\hline Chronic anticoagulation & $10.7 \%$ & $10.9 \%$ & 0.64 \\
\hline \multicolumn{4}{|l|}{ Procedural indication } \\
\hline Claudication & $67.0 \%$ & $66.8 \%$ & 0.81 \\
\hline Rest pain & $8.5 \%$ & $8.9 \%$ & 0.32 \\
\hline Tissue loss & $18.9 \%$ & $18.7 \%$ & 0.67 \\
\hline Acute ischemia & $5.60 \%$ & $5.6 \%$ & 0.99 \\
\hline \multicolumn{4}{|l|}{ Procedural urgency } \\
\hline Elective & $84.4 \%$ & $84.9 \%$ & 0.24 \\
\hline Urgent & $13.7 \%$ & $13.2 \%$ & 0.26 \\
\hline Emergent & $1.9 \%$ & $1.8 \%$ & 0.74 \\
\hline Arterial access site & & & 0.79 \\
\hline Femoral & $97.8 \%$ & $97.8 \%$ & \\
\hline Other & $2.2 \%$ & $2.2 \%$ & \\
\hline Access site complication & $3.3 \%$ & $3.48 \%$ & 0.46 \\
\hline
\end{tabular}

$P C l$, percutaneous coronary intervention; $S D$, standard deviation. 
the risk score to all patients in the VQI dataset and comparing ASC rates in patients receiving bivalirudin or a vascular closure device (VCD) or both bivalirudin and a VCD to those receiving manual pressure alone. Multiple procedures on unique patients were included, but procedures with data missing across any of the eight score covariates were excluded. Alpha level $\leq 0.05$ was considered significant for all analyses. All statistical analysis was done using SAS Version 9.2 (SAS Institute Inc., Cary, NC).

\section{RESULTS}

A total of 27,977 patients with unique PVI met the inclusion criteria. Patients in the derivation cohort had similar clinical and demographic characteristics compared with those in the validation cohort (Table 3). ASC occurred in 3.3\% $(n=650)$ of patients in the derivation cohort and in $3.48 \%(\mathrm{n}=289)$ in the validation cohort ( $\mathrm{P}=0.46$ for cross-cohort comparisons).

\section{Predictors of ASC and Model Derivation}

Univariate relationships between demographic/ preprocedural characteristics and ASC were age $>70$ years, female gender, white race, body mass index $<18.5$, nonsmoking history, diabetes treated with insulin, peritoneal or hemodialysis, bedridden preoperative ambulatory status, prior minor lower extremity amputation, prior aneurysm repair, procedural indication of claudication and nonfemoral arterial access site (Table 4). Multivariable predictors of ASC in the derivation cohort (Table 5) included age $>70$, female gender, white race, diabetes treated with insulin, bedridden ambulatory status, prior minor amputation, procedural indication of claudication and nonfemoral arterial access site (model c-statistic $=0.637)$. Based on the $\beta$ coefficient, a weighted integer value was given to each of the predictors (Figure 2) and eight points were added to each individual score to maintain totals greater than or equal to zero. Two predictors, insulin-treated diabetes and prior minor amputation, were assigned negative values as they were found to be protective of ASC.

The novel finding of insulin-managed diabetes being protective for ASC compared to nondiabetics and diabetics managed on oral hypoglycemic medications was further evaluated by propensity matching. A cohort of 4,091 patients in each treatment group, balanced for clinical, demographic and procedural characteristics, revealed a lower rate of ASC among insulin-treated diabetic patients $(2.71 \%$ vs. $3.72 \%$; OR: $0.723,95 \%$ CI: $0.564-0.927, \mathrm{P}=0.011)$. A separate propensity analysis comparing complication rates among diabetics and nondiabetics in a balanced cohort of 5,521 patients showed similar ASC rates (3.37\% vs. 3.52\%; OR: 0.955, 95\% CI: 0.774-1.179, $\mathrm{P}=0.67)$.

Scores were subsequently grouped into three risk groups: Low risk (score of 0 to $15 ; 5,845$ [29.7\%] patients with ASC rate of $2.0 \%$ ), moderate risk (score of 16 to $27 ; 12,510$ [63.6\%] patients with ASC rate of $3.49 \%$ ), and high risk (score of 28 to $42 ; 1,328$ [6.75\%] patients with ASC rate of 7.23\%) (Figure 3A, 3B). ASC requiring intervention (blood transfusion, thrombin injection or surgical repair) occurred in $0.85 \%(n=167)$ of patients in the derivation cohort, specifically $0.56 \%(\mathrm{n}=33)$ of low-risk patients, $0.82 \%$ $(n=102)$ of moderate-risk patients and $2.41 \%(n=32)$ of high-risk patients (Figure 3C).

\begin{tabular}{|lc|c|}
\hline \multicolumn{1}{|c|}{ Risk Factor } & $\begin{array}{c}\text { Integer } \\
\text { Score }\end{array}$ & \\
\hline Age $>70$ years & 4 & \\
Female Gender & 5 & \\
White Race, Non-Hispanic & 7 & \\
Preoperatively Bedridden & 8 & \\
Diabetic on Insulin & -3 & \\
Prior Minor Amputation & -5 & \\
PVI Indication of Claudication & 5 & \\
Nonfemoral Arterial Access & 5 & \\
& & $\mathbf{+ 8}$ \\
\hline \multicolumn{2}{|c|}{ Total } & \\
\hline
\end{tabular}

\begin{tabular}{|c|c|c|}
\hline $\begin{array}{c}\text { Risk } \\
\text { Score }\end{array}$ & Group & $\begin{array}{c}\text { Risk, } \\
\%\end{array}$ \\
\hline $0-15$ & Low & 1.94 \\
$16-27$ & Moderate & 3.37 \\
$28-42$ & High & 5.06 \\
\hline
\end{tabular}

Figure 2. Integer-based risk score to predict access site hematoma after peripheral vascular intervention (PVI). The sum of points for the risk factors present in an individual corresponds to the risk for in-hospital access site complications. Eight points are added to every patient's score in order to maintain total equal to or greater than zero. 
Table 4. Univariate relationship between baseline characteristics and access site complications in derivation cohort

\begin{tabular}{|c|c|c|c|}
\hline & $\begin{array}{c}\text { No ASC } \\
(n=19,033)\end{array}$ & $\begin{array}{c}\text { ASC } \\
(n=650)\end{array}$ & $P$ \\
\hline Age & & & $<0.001$ \\
\hline$\leq 70$ years & $58.17 \%$ & $46.15 \%$ & \\
\hline$>70$ years & $41.83 \%$ & $53.85 \%$ & \\
\hline Female & $41.19 \%$ & $55.08 \%$ & $<0.001$ \\
\hline Race & & & $<0.001$ \\
\hline White & $78.96 \%$ & $86.62 \%$ & \\
\hline Other & $21.04 \%$ & $13.38 \%$ & \\
\hline Body mass index & & & 0.003 \\
\hline$<18.5$ years & $4 \%$ & $6.31 \%$ & \\
\hline$\geq 18.5$ years & $96 \%$ & $93.69 \%$ & \\
\hline Smoking status & & & 0.025 \\
\hline No smoking & $20.67 \%$ & $24.31 \%$ & \\
\hline Prior/current & $79.33 \%$ & $75.69 \%$ & \\
\hline History of hypertension & $87.04 \%$ & $88 \%$ & 0.47 \\
\hline Diabetes & & & $<0.001$ \\
\hline None/on oral hypoglycemic & $73.32 \%$ & $81.54 \%$ & \\
\hline On insulin & $26.68 \%$ & $18.46 \%$ & \\
\hline Documented coronary artery disease & $30.1 \%$ & $28.35 \%$ & 0.34 \\
\hline Peritoneal dialysis or hemodialysis & $7.02 \%$ & $4.77 \%$ & 0.026 \\
\hline Symptomatic congestive heart failure & $6.96 \%$ & $5.69 \%$ & 0.21 \\
\hline Preoperative ambulatory status & & & 0.021 \\
\hline Ambulatory & $99.26 \%$ & $98.46 \%$ & \\
\hline Bedridden & $0.74 \%$ & $1.54 \%$ & \\
\hline Prior subinguinal bypass & $16.05 \%$ & $16.31 \%$ & 0.86 \\
\hline Prior peripheral vascular intervention & $29.57 \%$ & $27.23 \%$ & 0.20 \\
\hline Prior minor lower extremity amputation & $7.84 \%$ & $3.69 \%$ & $<0.001$ \\
\hline Prior major lower extremity amputation & $4.36 \%$ & $3.54 \%$ & 0.31 \\
\hline Procedural indication & & & 0.047 \\
\hline Claudication & $35.29 \%$ & $39.08 \%$ & \\
\hline Other & $64.71 \%$ & $60.92 \%$ & \\
\hline Procedural urgency: emergent & $1.88 \%$ & $2.46 \%$ & 0.29 \\
\hline Nonfemoral arterial access site & $2.12 \%$ & $3.69 \%$ & 0.007 \\
\hline
\end{tabular}

ASC, access site complication.

Table 5. Multivariate model generated in the derivation cohort

\begin{tabular}{lcccc}
\hline & Odds ratio & 95\% Cl & $\boldsymbol{\beta}$ coefficient & $\boldsymbol{P}$ \\
\hline Age $>$ 70 years & 1.516 & $1.290-1.783$ & 0.416 & $<0.0001$ \\
Female gender & 1.656 & $1.428-1.389$ & 0.503 & $<0.0001$ \\
White race, non-Hispanic & 1.962 & $1.217-3.163$ & 0.674 & 0.0057 \\
Preoperatively bedridden & 2.222 & $1.147-4.303$ & 0.799 & 0.0179 \\
Diabetic on insulin & 0.754 & $0.611-0.931$ & -0.282 & -0.491 \\
Prior minor amputation & 0.612 & $0.400-0.937$ & 0.0087 \\
Procedural indication of claudication & 1.711 & $1.010-2.899$ & 0.0237 \\
Nonfemoral arterial access & 1.657 & $1.085-2.530$ & 0.505 & 0.0457 \\
\hline
\end{tabular}

$\mathrm{Cl}$, confidence interval. 

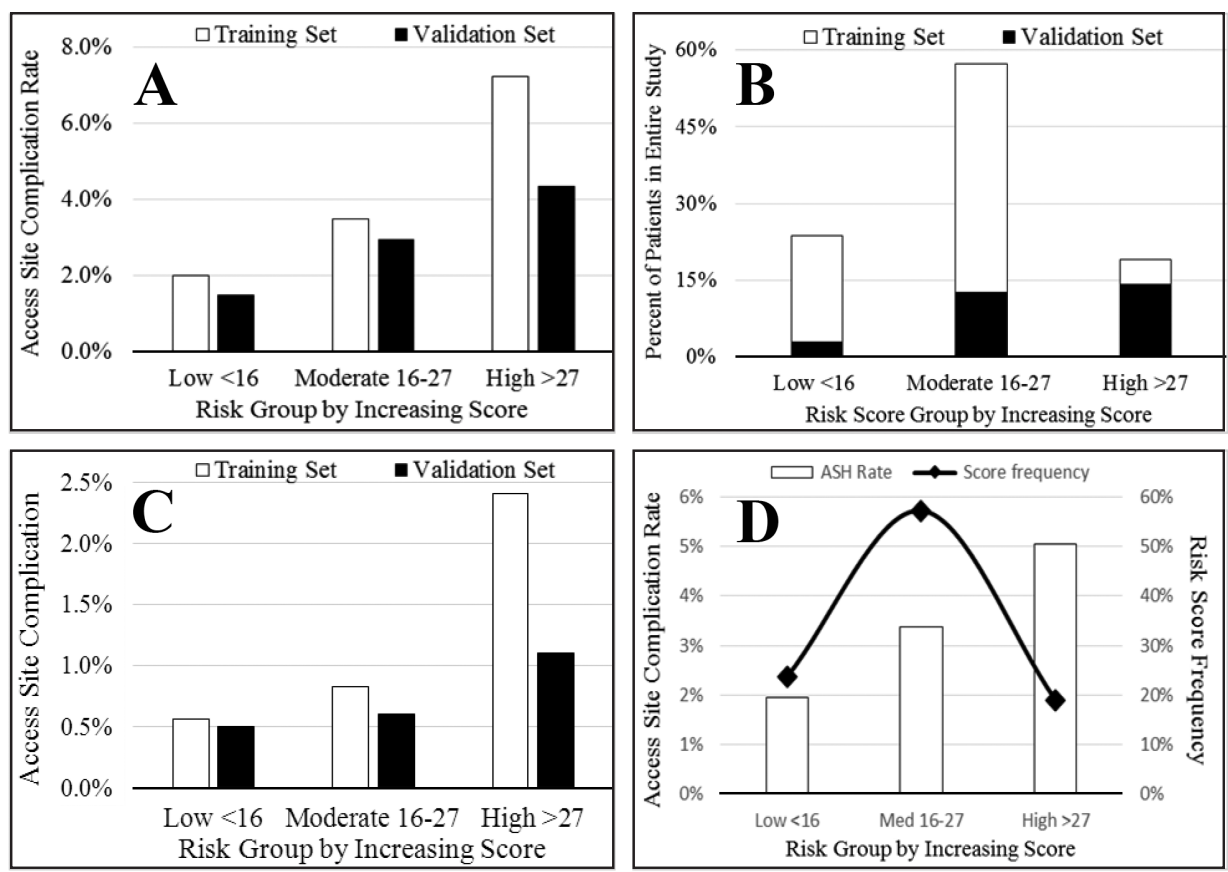

Figure 3. Access site complication (ASC) rate and frequency in derivation and validation cohorts by calculated risk score group. A: Observed ASC rate by calculated risk score and study cohort. B: Overall ASC frequency by calculated risk score and study cohort. C: Frequency of ASC requiring intervention (blood transfusion, thrombin injection or surgical repair) by risk score and study cohort. D: Access site complication rate and frequency by risk score in combined training and validation cohort.

\section{Model Validation}

ASC occurred in $1.5 \%$ of the low-risk group, $3.0 \%$ of the moderate-risk group and $4.3 \%$ of the highrisk group; risk group frequency was $9.7 \%, 42.4 \%$ and $48.0 \%$, respectively. The discriminatory power of the risk model was confirmed by the validation dataset (Brier score $=0.033$ ), for which the rate of ASC requiring intervention was $0.83 \%$ (69 patients), specifically $0.50 \%(\mathrm{n}=4), 0.60 \%(\mathrm{n}=21)$, and $1.10 \%$ $(n=44)$ of patients in the low-, medium- and high-risk groups, respectively. Figure 3D shows the mean ASC rates and clinical risk scores for the cohorts combined: $1.9 \%$ for low risk ( $23.8 \%$ score frequency), $3.4 \%$ for moderate risk (57.3\% score frequency) and $5.1 \%$ for high risk (19.0\% score frequency).

\section{Risk Score and Bleeding Avoidance Strategies}

Manual compression, bivalirudin, VCD and dual bleeding avoidance strategy (BAS) with bivalirudin plus VCD were used in $48.2 \%, 4.8 \%, 43.7 \%$ and $3.3 \%$ of patients, respectively. Overall, ASC was less frequent in patients who received VCD $(2.51 \%$; $\mathrm{P}<0.001)$ and dual BAS $(1.32 \%$; $<<0.001)$ compared with patients who had manual compression alone (3.98\%), but of similar frequency in patients receiving bivalirudin alone $(3.46 \% ; \mathrm{P}=0.295)$ (Figure 4). In a subpopulation analysis of patients at low predicted preprocedural risk, those who received bivalirudin alone had significantly higher ASC frequency than all other bleeding avoidance strategies, including manual compression alone $(4.60 \%$ vs. $1.85 \% ; \mathrm{P}=0.013)$. However, ASC was less frequent when bivalirudin was used together with a VCD compared with VCD use alone in moderate-risk $(1.33 \%$ vs. $2.50 \% ; \mathrm{P}<0.001)$ and high-risk $(1.56 \%$ vs. $3.64 \% ; \mathrm{P}<0.001)$ groups. Compared with other risk groups, patients at high predicted preprocedural risk had the lowest odds ratio from use of a VCD (OR: 0.620, 95\% CI: 0.546-0.705, $\mathrm{P}<0.001$ ) or dual BAS (OR: 0.322, 95\% CI: 0.193$0.541, \mathrm{P}<0.001)$ versus patients who had manual compression alone. A VCD alone was least used in high-risk patients (39\% vs. $45 \%$ in low-risk and $44 \%$ in moderate-risk; $\mathrm{P}<0.001$ ); use of dual BAS was not significantly different among risk groups.

\section{DISCUSSION}

The current study developed and validated a risk tool in 27,977 patients undergoing PVI procedures to identify patients at low, medium and high risk of developing in-hospital ASC. The variables in the risk tool are female gender, age $>70$, white race, bedridden ambulatory status, insulin-treated diabetes mellitus, prior minor amputation, procedural indication of claudication and nonfemoral arterial access site. Although many studies have examined predictors of post-PCI bleeding complications and developed 


\begin{tabular}{|c|c|c|c|}
\hline Risk Group & Treatment & OR, $95 \% \mathrm{Cl}$ & OR (95\% Cl), p \\
\hline \multirow{3}{*}{$\begin{array}{l}\text { Low } \\
\qquad(\mathrm{n}=5,049)\end{array}$} & Bivalirudin & & $2.562(1.190-5.516), 0.016$ \\
\hline & Closure Device & $\bullet$ & $0.870(0.562-1.346), 0.531$ \\
\hline & Bivalirudin and $C D$ & $\rightarrow$ & $0.601(0.145-2.495), 0.483$ \\
\hline \multirow{3}{*}{$\begin{array}{l}\text { Moderate } \\
(\mathrm{n}=23,824)\end{array}$} & Bivalirudin & $\leftarrow$ & $0.808(0.575-1.136), 0.220$ \\
\hline & Closure Device & $\bullet$ & $0.639(0.548-0.744),<0.001$ \\
\hline & Bivalirudin and $C D$ & 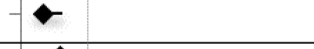 & $0.335(0.184-0.612),<0.001$ \\
\hline \multirow{3}{*}{$\begin{array}{l}\text { High } \\
(\mathrm{n}=4,627)\end{array}$} & Bivalirudin & $\bullet$ & $0.586(0.329-1.043), 0.069$ \\
\hline & Closure Device & $\bullet$ & $0.531(0.399-0.707),<0.001$ \\
\hline & Bivalirudin and $C D$ & $\bullet$ & $0.223(0.055-0.910), 0.037$ \\
\hline \multirow{4}{*}{$\begin{array}{l}\text { Overall } \\
(n=34,616)\end{array}$} & Bivalirudin & $\leftarrow$ & $0.864(0.658-1.136), 0.296$ \\
\hline & Closure Device & $\bullet$ & $0.620(0.546-0.705),<0.001$ \\
\hline & Bivalirudin and $C D$ & $\bullet$ & $0.322(0.193-0.541),<0.001$ \\
\hline & & 3 & 5 \\
\hline
\end{tabular}

Figure 4. Subpopulation differential treatment effect compared to group receiving manual compression alone. Highand moderate-risk patients had less access site complications with the use of closure devices and closure devices plus bivalirudin compared to patients receiving heparin and manual pressure alone. Patients at low preprocedural risk did not have less access site complications with any bleeding avoidance strategy compared to those who received heparin and manual pressure alone; in fact those who received bivalirudin and manual pressure had higher complication rates. $C D$, closure device; $\mathrm{Cl}$, confidence interval; $O R$, odds ratio. algorithms to stratify patient risk, this study is the first to do so in the post-PVI population. ${ }^{6-11}$ Preprocedural estimation of a patient's risk may allow clinicians to modify their practice to improve patient outcomes, as has been demonstrated in PCI studies. ${ }^{14,15}$

\section{Predictors of Access Site Complication}

Despite different patient population and outcome measures, the current risk tool shares age, female gender and procedural indication with nearly all PCI bleeding models. ${ }^{6-11}$ Prior minor amputation and preoperative bedridden status, which likely reflect disease severity and patient frailty, respectively, are predictors of ASC post-PCI. White race was predictive of bleeding, and disparity in bleeding rates among races has been previously identified in PVI, PCI and vascular interventions. ${ }^{5,16,17}$ Nonfemoral arterial access in PVI also has been associated with ASC and may be related to transbrachial access, which is associated with puncture site complications in PCI. ${ }^{5,18-20}$ Two factors - diabetes treated with insulin and prior minor amputation - proved protective against ASC when compared to all other patients in multivariate analysis, and this relationship also was observed in insulin-treated diabetics after propensity matching of preprocedural and procedural variables. This is a novel finding that differs from predictors in patients following PCI. The authors hypothesize that this may be explained by the biochemical and biomechanical changes studied in vitro that increase in the stability of aortic collagen, resulting in increased tensile strength of vessels. ${ }^{8,9,21}$ Further studies are warranted to elucidate if this relationship holds in peripheral arteries. Insulin therapy in diabetics may serve as a measure of increased disease duration and severity (as compared to diabetics treated with oral agents); similarly, a history of minor amputation may be more likely in advanced vasculopaths. Again, these are hypotheses; the mechanism of protection is beyond the scope of this investigation.

Although there was a relationship between dialysis and ASC on univariate analysis, multivariate analysis revealed no relationship between dialysis, glomerular function or creatinine and ASC. This differs from previously cited PCI risk scores and may be explained by the fact that renal dysfunction, as a bleeding diathesis, may increase non-access site bleeding, which was not included in our study. Similarly, most PCI bleeding scores include anemia as a bleeding predictor, a relationship not held in the VQI population. This, again, may be due to non-access site bleeding, including gastrointestinal bleeding in patients with prior bleeding disorders, which has been shown to increase post-PCI bleeding. ${ }^{7}$ Heart failure is the most important predictor of bleeding, presumably including ASC, in most PCI risk tools due to associated comorbidities. These include postprocedural intra-aortic balloon pump placement, which has been associated with a greater than eight times higher risk of post-PCI bleeding. ${ }^{7}$ 
Predicting the use of intra-aortic balloon pumps in patients with preprocedural signs of cardiogenic shock and non-access site bleeding complication in those with prior hemorrhagic diathesis also may explain the slightly higher c-statistics obtained in PCI bleeding risk tools.

\section{Bivalirudin/VCD}

The purpose of this tool was to estimate preprocedural risk for post-PVI ASC in order to guide clinicians' use of adjunct bleeding avoidance strategies to improve patient safety. We realize that procedural characteristics can change intraprocedural characteristics, including the use of VCDs and anticoagulants, however these were not included in the modeling process due to the potential for selection bias and the potential for incorrect dosing resulting in increased bleeding rates. ${ }^{11}$ The unadjusted subpopulation analysis comparing efficacy of bleeding avoidance strategies in PVI mirrored many findings in the National Cardiovascular Data Registry population studied for PCI. ${ }^{22,23}$ Overall, patients who received bivalirudin alone tended to have fewer ASC, despite this effect not being significant in the low preprocedural risk group. Patients who received a VCD with or without bivalirudin were less likely to develop ASC, especially among those at higher calculated risk. We also found a treatment paradox in that highrisk patients were less likely to receive a VCD. In this unmatched analysis, bivalirudin when used alone was not associated with lower ASC rates compared with patients receiving manual compression alone. The ENDOvascular Interventions With AngioMAX (ENDOMAX) trial may elucidate differences in the intrinsic risk of hemorrhagic complication between heparin and bivalirudin. ${ }^{24}$

\section{Study Limitations}

Among this study's strengths are the large, unselected, multicenter, real-world population analyzed and the quality of the registry-based data. Certain study limitations do warrant discussion, including the lack of accounting for within-hospital clustering and bleeding complications beyond the arterial access site or after discharge. Institutional variability may result in underreporting of post-PVI ASC, and other procedure-related bleeding complications are not adjudicated independently by the VQI. Furthermore, the retrospective nature of the study conveys inherent limitations, and the multivariable analysis performed may not have accounted for all relevant variables resulting in unmeasured confounding. Lastly, it was not possible to explore the relationship between bleeding and dosage, timing and duration of antithrombotic agents. This may be an important factor, as a recent analysis of post-PCI bleeding determined that maximum in-laboratory activated clotting time was the second most important predictor of bleeding in that population. ${ }^{25}$ Future studies are necessary to elucidate these questions.

\section{CONCLUSIONS}

Individual risk level for access site complications in patients undergoing peripheral vascular intervention may be predicted prior to the procedure. We developed and validated a simple tool that combines eight factors to stratify this hazard. Preprocedural ASC risk assessment could facilitate the individualized selection of antithrombotic therapy and use of closure devices to decrease post-PVI complications.

\section{Patient-Friendly Recap}

- Complications related to skin punctures for arterial access are common following vascular procedures and can result in hospitalization and death.

- The authors hypothesized a clinically applicable risk score could be developed by retrospectively analyzing data from thousands of peripheral vascular interventions (PVI).

- Six patient factors that significantly increased risk of site complications and two others that decreased risk were identified.

- The authors weighed these factors to create a risk score that helps physicians determine how best to avoid subsequent internal bleeding and other complications in patients receiving PVI.

\section{Acknowledgments}

The authors express their gratitude to the health care professionals involved in the Vascular Quality Initiative, Jennifer Pfaff and Susan Nord of Aurora Cardiovascular Services for editorial assistance, and Brian Miller and Brian Schurrer of Aurora Sinai Medical Center for assistance with the figures. 


\section{Funding Sources}

Dr. Jahangir's work is partly supported by the National Heart, Lung, and Blood Institute (R01 grants HL089542 and HL101240). This study was funded by the Sullivan Cardiac Research Award provided by the Aurora Health Care Foundation.

\section{Conflicts of Interest}

None.

\section{References}

1. Shammas NW, Shammas GA, Jerin M, Dippel EJ, Shammas AN. In-hospital safety and effectiveness of bivalirudin in percutaneous peripheral interventions: data from a real-world registry. J Endovasc Ther. 2010;17:31-6. CrossRef

2. Sheikh IR, Ahmed SH, Mori N, et al. Comparison of safety and efficacy of bivalirudin versus unfractionated heparin in percutaneous peripheral intervention: a single-center experience. JACC Cardiovasc Interv. 2009;2:871-6. CrossRef

3. Walker S, Beasley C, Reeves M. A retrospective study on the use of heparin for peripheral vascular intervention. Perspect Vasc Surg Endovasc Ther. 2012;24:63-9. CrossRef

4. Kasapis C, Gurm HS, Chetcuti SJ, et al. Defining the optimal degree of heparin anticoagulation for peripheral vascular interventions: insight from a large, regional, multicenter registry. Circ Cardiovasc Interv. 2010;3:593-601. CrossRef

5. Ortiz D, Jahangir A, Singh M, Allaqaband S, Bajwa TK, Mewissen MW. Access site complications after peripheral vascular interventions: incidence, predictors, and outcomes. Circ Cardiovasc Interv. 2014;7:821-8. CrossRef

6. Mehran R, Pocock SJ, Nikolsky E, et al. A risk score to predict bleeding in patients with acute coronary syndromes. J Am Coll Cardiol. 2010;55:2556-66. CrossRef

7. Nikolsky E, Mehran R, Dangas G, et al. Development and validation of a prognostic risk score for major bleeding in patients undergoing percutaneous coronary intervention via the femoral approach. Eur Heart J. 2007;28:1936-45. CrossRef

8. Subherwal S, Bach RG, Chen AY, et al. Baseline risk of major bleeding in non-ST-segment-elevation myocardial infarction: the CRUSADE (Can Rapid risk stratification of Unstable angina patients Suppress Adverse outcomes with Early implementation of the ACC/AHA Guidelines) Bleeding Score. Circulation. 2009;119:1873-82. CrossRef

9. Mathews R, Peterson ED, Chen AY, et al. In-hospital major bleeding during ST-elevation and non-ST-elevation myocardial infarction care: derivation and validation of a model from the ACTION Registry $^{\circledR}$-GWTG ${ }^{\mathrm{TM}}$. Am J Cardiol. 2011;107:1136-43. CrossRef

10. Rao SV, McCoy LA, Spertus JA, et al. An updated bleeding model to predict the risk of post-procedure bleeding among patients undergoing percutaneous coronary intervention: a report using an expanded bleeding definition from the National Cardiovascular Data Registry CathPCI Registry. JACC Cardiovasc Interv. 2013;6:897-904. CrossRef

11. Mehta SK, Frutkin AD, Lindsey JB, et al. Bleeding in patients undergoing percutaneous coronary intervention: the development of a clinical risk algorithm from the National Cardiovascular Data Registry. Circ Cardiovasc Interv. 2009;2:222-9. $\underline{\text { CrossRef }}$
12. Shammas NW, Allie D, Hall P, et al. Predictors of in-hospital and 30-day complications of peripheral vascular interventions using bivalirudin as the primary anticoagulant: results from the APPROVE Registry. J Invasive Cardiol. 2005;17:356-9.

13. Cronenwett JL, Kraiss LW, Cambria RP. The Society for Vascular Surgery Vascular Quality Initiative. J Vasc Surg. 2012;55:1529-37. CrossRef

14. Rao SC, Chhatriwalla AK, Kennedy KF, et al. Pre-procedural estimate of individualized bleeding risk impacts physicians' utilization of bivalirudin during percutaneous coronary intervention. J Am Coll Cardiol. 2013;61:1847-52. CrossRef

15. Strauss C, Porten B, Chavez I, et al. Real time decision support to guide percutaneous coronary intervention bleeding avoidance strategies reduces peri-procedural complications and improves costs. (abstr.) J Am Coll Cardiol. 2013;61(10_S):E1525. CrossRef

16. Mehta RH, Parsons L, Rao SV, Peterson ED; National Registry of Myocardial Infarction (NRMI) Investigators. Association of bleeding and in-hospital mortality in black and white patients with ST-segment-elevation myocardial infarction receiving reperfusion. Circulation. 2012;125:1727-34. CrossRef

17. Brown HA, Sullivan MC, Gusberg RG, Dardik A, Sosa JA, Indes JE. Race as a predictor of morbidity, mortality, and neurologic events after carotid endarterectomy. J Vasc Surg. 2013;57:1325-30. CrossRef

18. Lorenzoni R, Roffi M. Transradial access for peripheral and cerebrovascular interventions. J Invasive Cardiol. 2013;25:529-36.

19. Baklanov DV, Kim S, Marso SP, Subherwal S, Rao SV. Comparison of bivalirudin and radial access across a spectrum of preprocedural risk of bleeding in percutaneous coronary intervention: analysis from the national cardiovascular data registry. Circ Cardiovasc Interv. 2013;6:347-53. CrossRef

20. Kiemeneij F, Laarman GJ, Odekerken D, Slagboom T, van der Wieken R. A randomized comparison of percutaneous transluminal coronary angioplasty by the radial, brachial and femoral approaches: the access study. J Am Coll Cardiol. 1997;29:1269-75. CrossRef

21. Andreassen TT, Oxlund H. Changes in collagen and elastin of the rat aorta induced by experimental diabetes and food restriction. Acta Endocrinol (Copenh). 1987;115:338-44. CrossRef

22. Daugherty SL, Thompson LE, Kim S, et al. Patterns of use and comparative effectiveness of bleeding avoidance strategies in men and women following percutaneous coronary interventions: an observational study from the National Cardiovascular Data Registry. J Am Coll Cardiol. 2013;61:2070-8. $\underline{\text { CrossRef }}$

23. Marso SP, Amin AP, House JA, et al. Association between use of bleeding avoidance strategies and risk of periprocedural bleeding among patients undergoing percutaneous coronary intervention. JAMA. 2010;303:2156-64. CrossRef

24. Wayangankar SA, Abu-Fadel MS, Aronow HD, et al. Hemorrhagic and ischemic outcomes after bivalirudin versus unfractionated heparin during carotid artery stenting: a propensity score analysis from the NCDR. Circ Cardiovasc Interv. 2013;6:131-8. CrossRef

25. Hillegass WB, Brott BC, Chapman GD, et al. Relationship between activated clotting time during percutaneous intervention and subsequent bleeding complications. Am Heart J. 2002;144:501-7. CrossRef

(C) 2016 Aurora Health Care, Inc. 